\title{
Pattern and Causes of Hearing Loss Among the Patients Attending in an ENT OPD
}

\author{
*SMG Rabbani ${ }^{1}$, MA Chowdhury ${ }^{2}$, AM Shumon ${ }^{3}$, N Yasmeen ${ }^{4}$ \\ M Rashid ${ }^{5}$, M Nuruzzaman 6 , N Ahmed $^{7}$ \\ ${ }^{1}$ Dr. SM Golam Rabbani, Associate Professor (CC) and Head, Otolaryngology-Head \& Neck Surgery, \\ Tairunnessa Memorial Medical College \& Hospital, Boardbazar, Gazipur, Bangladesh. Email: \\ drsmgrabbani39@gmail.com \\ ${ }^{2}$ Prof. Dr. M. Alamgir Chowdhury, Professor \& Head, Otolaryngology - Head \& Neck Surgery, \\ Anwer Khan Modern Medical College, Dhaka, Bangladesh. \\ ${ }^{3}$ Dr. Ahmed Minhaz Shumon, Associate Professor and Head, Otolaryngology - Head \& Neck Surgery, \\ Medical College for Women (MCW), Uttara, Dhaka, Bangladesh \\ ${ }^{4}$ Dr. Naseem Yasmeen, Associate Professor, Otolaryngology - Head \& Neck Surgery, \\ MCWH, Uttara, Dhaka, Bangladesh \\ ${ }^{5}$ Dr. Md. Abdur Rashid, Associate Professor \& Head, Ophthalmology, TMMCH, \\ Board bazar, Gazipur, Bangladesh \\ ${ }^{6}$ Dr. Md. Nuruzzaman, Assistant surgeon, Adaor union sub center, Hobigonj, Bangladesh. \\ ${ }^{7}$ Dr. Nasir Ahmed, Medical officer, ENT Dept, TMMCH Otolaryngology- Head \& Neck Surgery, \\ Tairunnessa Memorial Medical College Hospital, Boardbazar, Gazipur, Bangladesh
}

*Corresponding Author

\begin{abstract}
This cross sectional prospective study was carried out in the Department of OtolaryngologyHead \& Neck Surgery, Tairunessa Memorial Medical College Hospital (TMMCH), Boardbazar, Gazipur, Bangladesh in a period of 12 months from 01.01.2012 to 31.12.2012 among those complaining hearing loss attending in ENT OPD. The aim of the study was to find out pattern and causes of hearing loss. Two hundred cases of hearing impaired people were taken and the data were collected by interviewing the cases as per questionnaire from history, examinations \& investigation reports. The commonest type of hearing loss was conductive type. In the right ear 114 cases $(63.33 \%)$ of conductive type of deafness, 36 cases $(20 \%)$ of mixed type of deafness and 30 cases $(16.67 \%)$ of sensorineural type of deafness. In the left ear 106 cases $(61.62 \%)$ of conductive type of deafness, 40 cases $(23.25 \%)$ of mixed type of deafness and 26 cases $(15.13 \%)$ of sensorineural type of deafness. This study showed that females $(58 \%)$ were mostly affected than males $(42 \%)$ and garments workers (45\%) were commonest group of people. From this study we got both ears were involved by disease process in $76 \%$ of the patients and only right ear was $14 \%$ and only left ear was $10 \%$. The commonest cause of hearing loss is chronic suppurative otitis media. The ear diseases are common in our country but its diagnosis is usually delayed, till then certain amount of hearing loss has occurred. So awareness, early diagnosis and proper treatment are needed to improve the situation.
\end{abstract}

Key words: Deafness, otitis media

\section{Introduction}

In Bangladesh a lot of people have different type and degree of hearing impairment. It is one of the important causes that makes a person different form of handicap and detached him from the society ${ }^{1,2}$. Even a hearing impaired person become burden of the society. Hearing impairment is such an important issue that a deaf child cannot talk. It is congenital or 
acquired and according to degree of deafness it is mild, moderate, severe or profound. According to type of deafness it is conductive, sensorineural, mixed and even psychological1. We had assessed hearing impaired 200 patients. All the patients were underwent details history through ear, nose, throat and other systemic examination and relevant available investigations. Pure tone audiometry is one of the simple diagnostic tool and easy to perform but give valuable information regarding degree, type, configuration of hearing loss and further management planning. The WHO estimated in 2005 that there were 278 million people worldwide with bilateral moderate to profound hearing loss, of whom 62 million had deafness that began in childhood ${ }^{3-5}$. Two-thirds of people with moderate to severe hearing loss live in the developing countries. South East Asia has the largest of hearing impairment in world and houses one-thirds of the hearing impaired population. So it should be routinely done in those patients complaining hearing impairment.

\section{Materials and Methods}

It is a cross sectional prospective study. This study will be carried out in the department of Otolaryngology- Head \& Neck Surgery, Tairunnessa Memorial Medical College \& Hospital, Boardbazar, Gazipur, Bangladesh from 01.01.2012 to 31.12.2012 for 12 months. Clinically \& by investigation proved cases of hearing loss were included in the study. Psychogenic causes of hearing loss were excluded. 200 cases of hearing impaired people attending in the department of OtolaryngologyHead and Neck Surgery was the study population. Data collected by interviewing the cases as per questionnaire from history, examinations \& investigation reports of the patients.

- The symbols used on most audiograms are and abbreviation used in this study:

dB- decibel

TM- Tympanic membrane

PTA- Pure Tone Audiometry

HZ- Hertz

\section{Operational definitions}

I. Pure tone: A single frequency sound is called a pure tone, e.g. a sound of 500, 1000, 2000 $\mathrm{Hz}$.

ii. Frequency: It is the number of cycles per second. The unit of frequency is Hertz $(\mathrm{Hz})$ named after the German scientist Heinrich Rudolf Hertz.

iii. Pure tone average: It is average thresholds of hearing in the speech frequencies.

iv. Decibel (dB): It is $1 / 10$ th of a bel and is named after Alexander Graham Bell. It is a logarithmic unit and indicates ratio between two different intensities. One $\mathrm{dB}$ is equal to the least perceptive difference in sound detectable by human ear in frequencies concern with speech. In the clinical work the threshold of normal hearing is $0 \mathrm{~dB}$.

\section{ix. Degree of hearing loss measurement}

Mild: $20-40 \mathrm{~dB}$

Moderate: 41-60 dB

Severe: $61-80 \mathrm{~dB}$

Profound: $>81 \mathrm{~dB}$

\section{Results}

In this series most sufferers are in age group of 3rd decade $(60 \%)$. Female are more in this study $58 \%$. Garment workers are $90(45 \%)$ in our series.

Table-I: Involvement of ear in disease process $(n=100)$

\begin{tabular}{lcc}
\hline Ear involved & No. of patient & Percentage $(\%)$ \\
\hline Only right ear & 28 & 14 \\
Only left ear & 20 & 10 \\
Both ear & 152 & 76 \\
\hline
\end{tabular}

Table-II: Degree of hearing loss among the patients

\begin{tabular}{|c|c|c|c|c|}
\hline \multirow{2}{*}{$\begin{array}{l}\text { Degree of } \\
\text { hearing loss }\end{array}$} & \multicolumn{2}{|c|}{ Right ear $(n=180)$} & \multicolumn{2}{|c|}{ Left ear $(n=172)$} \\
\hline & $\begin{array}{l}\text { No. of } \\
\text { patients }\end{array}$ & $\begin{array}{l}\text { Percentage } \\
(\%)\end{array}$ & $\begin{array}{l}\text { No. of } \\
\text { patients }\end{array}$ & $\begin{array}{l}\text { Percentage } \\
(\%)\end{array}$ \\
\hline Mild & 98 & 54.44 & 106 & 61.62 \\
\hline Moderate & 46 & 25.54 & 38 & 22.09 \\
\hline Sever & 14 & 07.77 & 14 & 8.13 \\
\hline profound & 22 & 12.22 & 14 & 8.13 \\
\hline
\end{tabular}


Table-III: Type of hearing loss

\begin{tabular}{|c|c|c|c|c|}
\hline \multirow{2}{*}{$\begin{array}{l}\text { Type of } \\
\text { hearing loss }\end{array}$} & \multicolumn{2}{|c|}{ Right ear $(n=180)$} & \multicolumn{2}{|c|}{ Left ear $(n=172)$} \\
\hline & No. of pt. & $\begin{array}{l}\text { percentage } \\
(\%)\end{array}$ & No. of pt. & $\begin{array}{l}\text { Percentage } \\
(\%)\end{array}$ \\
\hline Conductive & 114 & 63.33 & 106 & 61.62 \\
\hline Sensorineural & 30 & 16.67 & 26 & 15.13 \\
\hline Mixed & 36 & 20.00 & 40 & 23.25 \\
\hline
\end{tabular}

Table-IV: Causes of hearing loss $(\mathrm{n}=100)$

\begin{tabular}{lcc}
\hline Causes of hearing loss & No. of patients & Percentage \\
\hline 1. Chronic Suppurative Otitis Media & 82 & 41 \\
2. Otitis Media with Effusion & 60 & 30 \\
3. Idiopathic Sudden Sensori-neural & 18 & 09 \\
$\quad$ Hearing Loss & 10 & \\
4. Idiopathic mixed deafness & 08 & 04 \\
5. Presbyacusis & 06 & 03 \\
6. Otosclerosis & 06 & 03 \\
7. Idiopathic Sudden Severe Sensori & & \\
$\quad$ neural Hearing Loss & 04 & 02 \\
8. Microtia and External Auditory & & 01 \\
$\quad$ Canal atresia & 02 & 01 \\
9. Meniere's disease & & \\
10. Traumatic rupture of Tympanic & 02 & \\
11. Otomycosis & & 02 \\
\hline
\end{tabular}

\section{Discussion}

Suspected hearing loss in all age group people should be promptly investigated. Accurate assessment of hearing is fundamental to diagnosis, investigation, treatment and rehabilitation. Through examination and skilled testing by trained personnel in a suitable test environment is the key to diagnosis the type, degree and other aspect of hearing impairment ${ }^{6-9}$. WHO also estimates that every year about 38,000 deaf children are born in this region ${ }^{10,11}$. G. G. Browning et al showed that prevalence of hearing impairment is $3.5 \%$ in the age group of $18-40$ years, $17.4 \%$ in the age group of $41-60$ years and $45.3 \%$ in the age group of 61 80 years ${ }^{4,12-14}$. In this study patient of 21-30 years age group are most commonly affected and it is $30 \%$. Next common age group is $31-40$ years and
$16 \%$ of the total patient in this age group, followed by $51-60$ years of age group is $14 \%, 11-20$ years of age group is $12 \%, 41-50$ years of age group is $12 \%$, more than 60 years of age group is $10 \%$, lastly $0-10$ years of age group in which only $06 \%$ patient. The dissimilarity is due to unawareness of our people about hearing impairment and as well as most of the patient of age related loss remain undiagnosed. Usually there is no sex difference in prevalence of ear disease. This study shows female sex is predominant, $58 \%$ female is affected by deafness in respect to $42 \%$ male.

In the occupation pattern the manual worker are 1.3 times more affected in conductive hearing impairment than the non-manual worker according to the result of a British study ${ }^{4,15}$. Our study reveals that garments workers $(45 \%)$ are commonest group of people that are affected by deafness then housewives (23\%), students $(17 \%)$ and followed by service holders (7\%), businessman (4\%) and cultivators (4\%). In our study total manual worker is $67 \%$ and rest of them is nonmanual worker. So our study is similar to that study. The result is similar with the $\mathrm{WHO}^{16-18}$.

From this study we got both ears were involved in disease process in $76 \%$ of the patients and only right ear was $14 \%$, only left ear was $10 \%$. So both ear involvements were more than unilateral. The prevalence of adult middle ear disease in the British population was obtained from the UK National Study of Hearing, a randomly selected prospective clinical study. An otoscopic diagnosis was made from the sample of 2708 British adults ${ }^{4}$. The prevalence of healed, inactive and active COM (Chronic otitis media) was 12, 2.6, and 1.5 percent, respectively and collectively $16.1 \%$. From this study we find CSOM is the commonest cause of hearing loss and it is $41 \%$. The difference of UK study from us is due to the fact is that they include all the people in their study but we take only the hearing impaired people ${ }^{14,19}$.

Zielhius et al. reviewed a total of 23 studies shows age-specific prevalence rates of OME up to ten years of age. The prevalence is bimodal with the first and largest peck of approximately $20 \%$ at two years of age. There after the prevalence declines, 
but there is a second peck of approximately $16 \%$ at around five years of age when majority of children start attending a primary school ${ }^{5}$. In this study second common cause of hearing impairment is OME and it accounts $30 \%$ of all causes. Our study is almost similar with the study above mentioned.

ISSSNHL (idiopathic sudden severe sensorineural hearing loss) is not an uncommon cause of hearing loss in Bangladesh. A number of Authors have proposed the definitions of ISSSNHL. One of the most adopted definitions is that of Wilson et al. that is at least $30 \mathrm{~dB}$ of hearing loss at three contiguous frequencies in less than three days ${ }^{18}$. More recently, a retrospective cross-sectional study from Taiwan estimated the incidence at approximately eight in 100,000 per year ${ }^{7}$. From this study we found 3 cases of ISSSNHL (idiopathic sudden severe sensorineural hearing loss), all are unilateral and left side is twice common than right ear involvement. The difference of Taiwan's study and us is due to the fact that they include all the people in their study but we take only the hearing impaired person.

The next common cause of hearing loss is Otosclerosis. The British National Study of Hearing says overall prevalence of Otosclerosis is $2 \%$ (CI 1.5, 2.7) with equal distribution between male and female ${ }^{14}$. Otosclerosis is found from this study $03 \%$ (06) which is statistically significant with that study. Presbyacusis or age related sensorineural hearing loss is almost invariably inevitable. In an individual over age of sixty, with normal examination findings asymmetrical (often predominantly high-tone) hearing loss, a diagnosis of presbyacusis or age related sensorineural hearing loss is fairly secure. Another study shows that 25 to $40 \%$ of population aged 60 or older has hearing impairment ${ }^{19}$. We found eight cases $(04 \%)$ of presbyacusis or age related sensorineural hearing loss. The dissimilarity between two studies because in perspective of Bangladesh the most of the cases of hearing loss remain undiagnosed as because of unawareness and unavailability of simple hearing test pure tone audiometry (PTA).

G. G. Browning et al showed that $16 \%$ of adults have mild $(21-40 \mathrm{~dB}), 4 \%$ a moderate $(41-60 \mathrm{~dB})$ and $1 \%$ severe $(61-80 \mathrm{~dB})$ impairment in both ears. If only the poorer hearing ear is considered, $26 \%$ have a mild, $9 \%$ have a moderate and $4 \%$ have a severe hearing impairment in that ear ${ }^{4}$. G. G. Browning et al also found that mild hearing loss is the commonest degree of hearing loss ${ }^{4}$ which is similar with our study. Another finding is type of hearing loss; commonest type is conductive type. In the right ear 114 cases $(63.33 \%)$ of conductive type of deafness, 36 cases (20\%) of mixed type of deafness and 30 cases $(16.67 \%)$ of sensorineural type of deafness and in the left ear 106 cases $(61.62 \%)$ of conductive type of deafness, 40 cases (23.25\%) of mixed type of deafness and 26 cases $(15.13 \%)$ of sensorineural type of deafness is found. So it is noteworthy that commonest type of deafness is conductive as $63.33 \%$ of right ear and $61.62 \%$ of left ear shows this type of deafness. Our study is similar with British study.

\section{Conclusion}

From this study it is concluded that the commonest type of hearing loss is conductive type, commonest degree of hearing loss is mild degree (21-40 dB) and common causes of hearing loss are CSOM and OME. As ear diseases are common in our country and most of the causes are preventable. We should take appropriate steps to manage the preventable hearing impairment to improve the situation. Conflict of Interest: We have no conflict of interest.

\section{References}

1. Lunner T. Cognitive function in relation to hearing aid use. International Journal of Audiology 2003; 42: S49-58.

2. Michael Gleeson: Scott-Browns, Otolaryngology \& Head-Neck Surgery; 7th edition; Hodder Arnold, London, 2008; 3: 3261-3275.

3. www.who.int/factsheet/fs300/en/index.html.

4. Browning GG, Gatehouse $S$. The prevalence of middle ear disease in the adult British population. Clinical Otolaryngology 1992; 17: 317-21.

5. Zeilhuis GA, Rach GH, Van Den Bach A et al. The prevalence of otitis media with effusion: A critical review of literature. Clinical Otolaryngology 1990; 15: $283-8$. 
AKMMC J 2013: 5(2)

6. Merchant SN, Adams JC, Nadal JB. Pathology and pathophysiology of idiopathic sudden sensorineural hearing loss. Otology and Neurotology 2005; 26: 151-60.

7. Wu CS, Lin HC, Chao PZ. Sudden sensorineural hearing loss in Japan Audiology and Neurotology 2006; 11: 151-6.

8. Wilson WR, Byl FD, Larid N. The efficacy of steroid in the treatment of idiopathic sudden hearing loss. A double-blind clinical study. Archives of Otolaryngology 1980; 106: 772-6.

9. IEC 60645-1. Electroacoustics- Audiological equipment. Part 1 - pure tone audiometers. Geneva: International Electrotechnical Commission.

10. Monerio de Castro Silva I, Feitosa MA. High frequency audiometry in young and older adults when conventional audiometry is normal. Rev Bras Otorhinolaryngol 2006; 72: 665-72.

11. Nasima A, Pran G D, Alauddin M. Neonatal Hearing Screening. Bangladesh J Otorhinolaryngol 2010; 16(1): 54-59.

12. Sek A, Alcantra J, Moore BC et al. Development of a fast method for determining psychophysical tuning curves. Int J Audiol. 2005; 44: 408-20.
SMG Rabbani, MA Chowdhury, AM Shumon et al

13. Huss M, Moore BCJ. Dead regions and noisiness of pure tones. Int J Audiol. 2005; 44: 599-611.

14. Gans D, Flexer C. Observer bias in the hearing testing of profoundly involved multiply handicapped children. Ear \& Hearing 1982; 3(6): 309-313.

15. Gerber S. The use of noise-making toys as audiometric devices. International Journal of Paediatric Otorhinolaryngology 1982; 4: 309-315.

16. Lovegrove R, Birtles G. Measurements of noisemaking toys and their application in infant hearing assessment. Australian Journal of Audiology 1983; 5(2): 47-54.

17. Poverty alleviation and empowerment through Microfinance: Two decades of experience Bangladesh. Rushidan Islam Rahman; Bangladesh Institute of Development Studies (BIDS), 57.

18. http://en.wikipedia.org/wiki/pure_tone audiome

19. Chowdhury MA, Alauddin M. Comparative study between tubo-tympanic and atticoantral types of chronic suppurative otitis media, Bulletin of Bangladesh Med Res Coun Bull 2002; 28(1); 36 - 44. 